\title{
Identifikasi Opinion Leader di Kalangan Mahasiswa untuk Produk Laptop
}

\author{
Pratiwi AE., Hakim MS., dan Rahmawati Y. \\ Departemen Manajemen Bisnis, Fakultas Bisnis dan Manajemen Teknologi, Institut Teknologi Sepuluh Nopember
}

(ITS)

email: arinaekapratiwi@gmail.com

\begin{abstract}
Abstrak - Perkembangan teknologi informasi dewasa ini semakin meningkat, hal ini ditandai oleh bertambahnya permintaan konsumen terhadap laptop. Pada umumnya, konsumen (terutama mahasiswa) melibatkan orang lain (Opinion Leader) dalam pembelian produk laptop. Maka dari itu perlu adanya identifikasi lebih lanjut mengenai Opinion Leader di kalangan mahasiswa untuk produk laptop. Penelitian ini bertujuan untuk mengetahui faktor yang mempengaruhi mahasiswa mempercayai Opinion Leader. Dalam penelitian ini menggunakan desain riset eksploratori dengan metode kualitatif. Strategi penelitian ini menggunakan strategi survei dengan cara wawancara kepada responden yang sudah memenuhi kategori. Hasil dari penelitian ini menunjukan bahwa dalam pembelian laptop mahasiswa melibatkan Opinion Leader. Faktor yang paling mempengaruhi mahasiswa mempercayai Opinion Leader adalah memahami masalah teknologi dan teman dari satu bidang.
\end{abstract}

Kata Kunci-Opinion Leader, Perilaku Konsumen.

\section{PENDAHULUAN}

$\mathrm{P}$ ERKEMBANGAN teknologi semakin canggih dengan menciptakan produk baru yang memiliki teknologi modern, salah satunya adalah teknologi informasi. Salah satu pengguna utama laptop adalah mahasiswa. Di Indonesia ditemukan bahwa $73,5 \%$ pengguna laptop adalah mahasiswa [1].

Produk Laptop merupakan high involvement product yang salah satunya melibatkan pertimbangan orang lain dalam membeli produk laptop. Keterlibatan orang lain dalam memilih laptop merupakan salah satu bentuk saluran komunikasi personal. Saluran komunikasi personal adalah saluran komunikasi yang melibatkan dua atau lebih individu secara langsung, baik secara tatap muka langsung (face to face), individu dengan pemirsa (person to audience), melalui telepon, atau melalui email [2].

Salah satu cara menumbuhkan komunikasi personal adalah mendukung adanya pemimpin opini (Opinion Leader). Opinion Leader dapat didefinisikan sebagai orang yang dapat mengarahkan beberapa pengaruh terhadap suatu keputusan yang akan diambil orang lain [3]. Opinion Leader memegang peranan yang penting. Jika Opinion Leader tidak menyukai suatu produk, mereka tidak akan merekomendasikan pada konsumen yang akan membeli produk tersebut[4]. Opinion Leader sebagai orang yang mempunyai keunggulan juga mempunyai karakteristik yaitu lebih inovatif dalam menerima ide baru, lebih tinggi pengenalan medianya (media exposure), dan lebih kosmopolit atau mempunyai pengetahuan dan wawasan yang luas.
Penelitian ini bertujuan untuk mengetahui faktor yang mempengaruhi mahasiswa mempercayai Opinion Leader. Sampai saat ini Opinion Leader di kalangan mahasiswa masih belum jelas dan belum banyak riset mengenai topik terkait. Penelitian ini dapat berkontribusi untuk mengetahui faktor apa saja yang membuat mahasiswa percaya Opinion Leader untuk produk laptop.

\section{TINJAUAN PUSTAKA}

Opinion Leader adalah Opinion Leader adalah suatu proses dimana seseorang dapat mempengaruhi tindakan dan sikap orang lain secara informal [5]. Dapat disimpulakan bahwa Opinion Leader adalah orang yang dapat mempengaruhi sikap dan perilaku orang lain dalam menentukan keputusan pembelian produk atau jasa, sehingga orang yang dipengaruhi oleh seorang Opinion Leader tertarik dan akhirnya mengambil keputusan untuk membeli.

Opinion Leader dapat mempengaruhi keputusan pembelian konsumen dalam produk atau jasa yang ditawarkan. Hasil dari penelitian [6], menemukan bukti bahwa banyak pekerjaan yang masih harus mengetahui konsep kepemimpinan opini, khususnya tentang bagaimana perilaku Opinion Leader mempengaruhi niat pembelian. Pemasar dianjurkan untuk dapat mengidentifikasi Opinion Leader yang memberikan rekomendasi kepada pelanggan.

Ciri-ciri dan sifat Opinion Leader dapat dipercaya karena memiliki kekuatan yaitu berupa keahlihan khusus secara teknis dan berkompeten, melakukan evaluasi dan perbandingan terhadap informasi sehingga mempunyai pengetahuan luas, dari segi sosial cenderung aktif sehingga proses komunikasi yang dilakukan akan lebih mudah dan komunikasi dengan orang lain lebih banyak, dan biasanya menjadi orang pertama yang membeli suatu produk, maka dari itu mereka termasuk orang yang berani memberikan pendapat dan mengatakan resiko dari produk atau jasa yang dibeli kepada orang lain yang belum atau akan membeli produk atau jasa tersebut [7].

\section{METODOLOGI PENELITIAN}

\section{A. Jenis Data}

Data yang digunakan dalam penelitian ini adalah data primer yakni hasil wawancara yang dilakukan kepada responden. Data primer dalam penelitian ini diperoleh dari wawancara secara mendalam kepada narasumber yaitu mahasiswa Institut Teknologi Sepuluh Nopember Surabaya (ITS). Terdapat 20 responden dalam penelitian ini yang mana 
responden di bagi dua, yaitu 15 responden sebagai responden mahasiswa ITS yang mengunakan laptop dan 5 responden yang merupakan Opinion Leader produk laptop.

\section{B. Pengumpulan Data}

Penelitian dilakukan dengan menggunakan metode survei melalui wawancara secara mendalam. Wawancara dilakukan dengan mendatangi lokasi responden yang sudah ditentukan sebelumnya. Pertanyaan bersifat terbuka yang mana terdapat pertanyaan yang sudah dibuat di pedoman wawancara dan terdapat pertanyaan yang tiba-tiba diajukan kepada responden untuk melengkapi data yang diperlukan.

Responden dari penelitian ini adalah pria dan wanita yang mempunyai frekuensi yaitu laki-laki sebanyak 7 orang, dan perempuan sebanyak 13 orang. Rata-rata usia responden dari penelitian ini anatara 18-23 tahun, yang mana di dominasi oleh responen berusia 21 tahun.

Terdapat 15 responden yang menggunakan laptop dan 5 responden yang merupakan Opinion Leader produk laptop. 15 responden yang menggunakan laptop dikatagorikan dengan kode R1 sampai R15 dan 5 responden yang merupakan Opinion Leader dikatagorikan dengan kode OL1 sampai OL5. Tabel 1 menyajikan 5 responden Opinion Leader yang mana 3 responden Opinion Leader merupakan rekomendasi dari 15 responden mahasiswa ITS dan berkontribusi dalam pembelian laptop R1-R15.

Tabel 1.

Responden yang Menggunakan Opinion Leader

\begin{tabular}{ccc}
\hline \hline No & Opinion Leader & Responden \\
\hline 1 & OL1 & R1, R2, R13 \\
2 & OL2 & - \\
3 & OL3 & R3, R5 \\
4 & OL4 & - \\
5 & OL5 & R14 \\
\hline \hline
\end{tabular}

Setelah mengumpulkan data peneliti melakukan reduksi data kepada 20 responden penelitian. Di dalam reduksi data terdapat verbatim wawancara yang mana peneliti mentransfer hasil wawancara dari suara ke dalam text. kemudian peneliti akan meredukdi data setelah verbatim wawancara selesai. Reduksi data dilakukan untuk mendapatkan data dari faktorfaktor mahasiswa percaya terhadap Opinion Leader produk laptop.

\section{ANALISIS DAN PEMBAHASAN}

\section{A. Faktor Mahasiswa Percaya Opinion Leader}

Responden penulis adalah 15 mahasiswa ITS Surabaya yang menggunakan laptop dengan kode responden R1-R15. Ada beberapa faktor yang membuat responden mempercayai Opinion Leader untuk membeli produk laptop. Tabel 2 menunjukan beberapa faktor yang membuat responden percaya kepada Opinion Leader produk laptop. Gambar 3 menyajikan gambaran faktor-faktor yang menyebabkan mahasiswa memeprcayai Opinion Leader produk laptop.
Tabel 2.

Pengelompokan Mahasiswa Percaya Opinion Leader

\begin{tabular}{|c|c|c|c|}
\hline No & Faktor & Deskripsi & $\begin{array}{c}\text { Responde } \\
\text { n yang } \\
\text { sepakat }\end{array}$ \\
\hline 1 & $\begin{array}{c}\text { Memahami masalah } \\
\text { Teknologi }\end{array}$ & $\begin{array}{c}\text { Dapat menjelaskan } \\
\text { teknologi yang sedang } \\
\text { berkembang untuk produk } \\
\text { laptop }\end{array}$ & $\begin{array}{l}\text { R1, R4, } \\
\text { R7, R11, } \\
\text { R13, R15 }\end{array}$ \\
\hline 2 & $\begin{array}{l}\text { Teman satu bidang } \\
\text { atau jurusan }\end{array}$ & $\begin{array}{l}\text { Memiliki kesamaan dalam } \\
\text { kegiatan sehari-hari. Untuk } \\
\text { mengerjakan tugas kuliah, } \\
\text { presentasi, desain atau } \\
\text { software yang digunakan }\end{array}$ & $\begin{array}{l}\text { R1, R4, } \\
\text { R7, R9, } \\
\text { R13, R14 }\end{array}$ \\
\hline 3 & $\begin{array}{c}\text { Up to date } \\
\text { mengenai informasi } \\
\text { laptop }\end{array}$ & $\begin{array}{l}\text { Memiliki informasi } \\
\text { mengenai merek laptop } \\
\text { terbaru, harga laptop yang } \\
\text { terjangkau dan kualitas } \\
\text { yang dimiliki laptop } \\
\text { tersebut }\end{array}$ & $\begin{array}{l}\text { R1, R7, } \\
\text { R11, R13, } \\
\text { R15 }\end{array}$ \\
\hline 4 & $\begin{array}{l}\text { Dapat memberikan } \\
\text { saran dengan baik }\end{array}$ & $\begin{array}{l}\text { Saran yang diberikan sesuai } \\
\text { dengan apa yang } \\
\text { dibutuhkan oleh responden } \\
\text { yang menanyakan } \\
\text { spesifikasi laptop }\end{array}$ & R5 \\
\hline 5 & $\begin{array}{l}\text { Berpengalaman } \\
\text { membeli laptop } \\
\text { yang bagus }\end{array}$ & $\begin{array}{l}\text { Laptop yang digunakan } \\
\text { bisa bertahan lama atau } \\
\text { awet sehingga tidak mudah } \\
\text { rusak dan kinerja laptop } \\
\text { tetap baik }\end{array}$ & R5, R9 \\
\hline 6 & $\begin{array}{l}\text { Suka bermain } \\
\text { games di laptop }\end{array}$ & $\begin{array}{l}\text { hobi bermain games di } \\
\text { laptop selalu mempunyai } \\
\text { informasi terbaik karena } \\
\text { spesifikasi laptop yang } \\
\text { digunakan untuk bermain } \\
\text { games sangat tinggi } \\
\text { sehingga dapat memberikan } \\
\text { rekomendasi laptop yang } \\
\text { baik }\end{array}$ & R5, R11 \\
\hline 7 & $\begin{array}{l}\text { Begabung dalam } \\
\text { komunitas tentang } \\
\text { teknologi }\end{array}$ & $\begin{array}{l}\text { Selalu mendiskusikan } \\
\text { produk laptop dengan } \\
\text { teknologi terbaru dan } \\
\text { menarik untuk diperhatikan } \\
\text { setiap orang yang bekeria }\end{array}$ & R9 \\
\hline 8 & $\begin{array}{c}\text { Bekerja pada bidang } \\
\text { Teknologi }\end{array}$ & $\begin{array}{l}\text { pada bidang teknologi akan } \\
\text { mengerti apa produk yang } \\
\text { mempunyai kualitas baik }\end{array}$ & $\mathrm{R} 11, \mathrm{R} 15$ \\
\hline 9 & $\begin{array}{l}\text { Mengikuti mata } \\
\text { kuliah mengenai } \\
\text { laptop }\end{array}$ & $\begin{array}{l}\text { Mengerti bagian-bagian } \\
\text { laptop dengan baik } \\
\text { sehingga dapat memberikan } \\
\text { rekomendasi laptop yang } \\
\text { bagus }\end{array}$ & R14 \\
\hline
\end{tabular}

Terdapat 9 faktor mahasiswa percaya Opinion Leader produk laptop yang ditemukan oleh peneliti dari hasil wawancara kepada responden. Faktor yang sering disebutkan adalah faktor memahami masalah teknologi dan faktor teman satu bidang atau jurusan. Sebanyak 6 responden dengan kode responden R1, R4, R7, R11, R13, R15 yang mempercayai Opinion Leader dengan faktor karena Opinion Leader mereka adalah orang yang memahami masalah teknologi. Memahami masalah teknologi adalah dimana orang yang menjadi Opinion Leader untuk produk laptop dapat menjelaskan apa saja teknologi yang sekarang sedang berkembang pada produk laptop. Berikut merupakan gambar 1 yang merupakan faktor mahasiswa mempercayai Opinion Leader. 


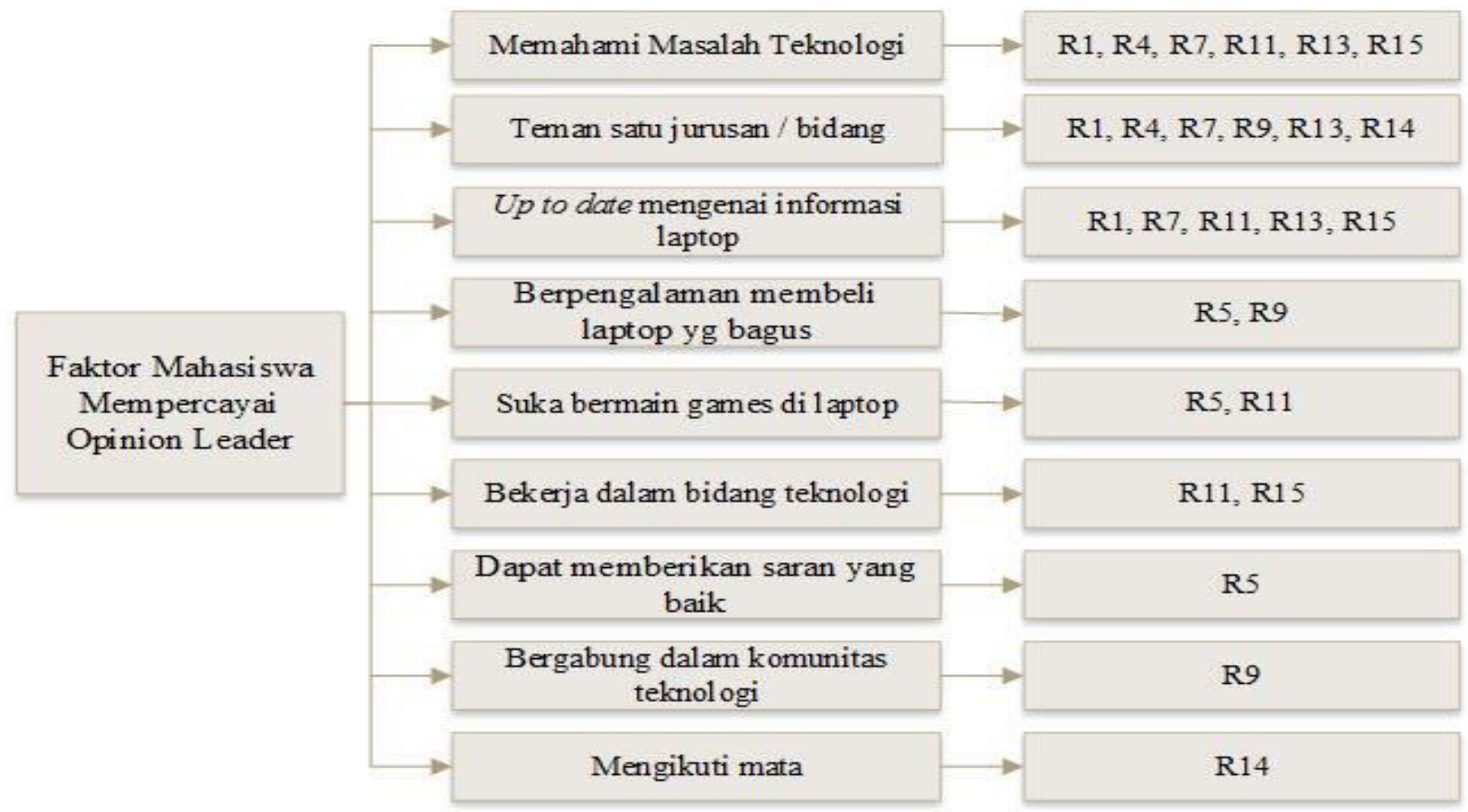

Gambar 1. Faktor Mahasiswa Mempercayai Opinion Leader.

Selain itu, responden tersebut juga dapat menjelaskan mengenai produk laptop secara jelas misalnya apa saja produk laptop yang bagus, merek laptop apa yang biasanya sering orang gunakan dan kualitas dari produk laptop itu sendiri. Selanjutnya sebanyak 6 responden juga yang menyebutkan faktor mempercayai Opinion Leader karena Opinion Leader tersebut teman satu bidang atau satu jurusan. Responden yang menyebutkan faktor tersebut adalah responden dengan kode R1，R4， R7， R9, R13, R14. Keenam responden tersebut mempercayai Opinion Leader produk laptop mereka karena responden dan orang yang menjadi Opinion Leader produk laptop bekerja pada kegiatan yang sama. Misalnya, untuk melakukan kegiatan kuliah seperti tugas, presentasi, desain dan software yang diperlukan karena kegiatan sehai-hari hampir sama dengan teman yang ada di satu bidang atau satu jurusan. Opinion Leader akan memberikan beberapa rekomendasi yang cocok untuk digunakan pada saat responden melakukan kegiatan kuliah.

Faktor ketiga yang sering disebutkan oleh responden adalah faktor bahwa Opinion Leader adalah orang yang up to date mengenai informasi laptop. Responden dengan kode R1, R7, R11, R13, R15 menyebutkan bahwa mereka mempercayai Opinion Leader produk laptop karena orang tersebut up to date terhadap informasi mengenai produk laptop. Misalnya, setiap kali responden menanyakan kebingungannya mengenai laptop yaitu merek apa yang paling terbaru, harga laptop terbaru yang terjangkau dan kualitas yang dimiliki laptop tersebut mereka mendapatkan jawaban dari orang yang mereka anggap selalu up to date mengenai informasi laptop.

Faktor keempat, sebanyak 2 responden dengan kode responden R5 dan R9 menyebutkan bahwa faktor yang membuat responden percaya terhadap Opinion Leader adalah Opinion Leader berpengalaman membeli laptop yang bagus.
Responden melihat bahwa laptop yang digunakan orang yang mereka anggap sebagai Opinion Leader adalah laptop yang bisa bertahan lama atau awet. Ketahanan laptop yang lama merupakan salah satu tipe produk laptop yag akan dibeli oleh pelanggan. Faktor selanjutnya adalah faktor suka bermain games di laptop. Faktor ini disebutkan oleh 2 responden dengan kode R5 dan R11. Dari hasil wawancara didapatkan bahwa responden mempercayai Opinion Leader produk laptop karena orang tersebut mempunyai hobi yaitu main games di laptop.

Responden mengatakan bahwa orang yang hobi bermain games di laptop selalu mempunyai informasi terbaik karena spesifikasi laptop yang digunakan untuk bermain games sangat tinggi. Dari informasi tersebut, responden mempercayai bahwa orang yang mempunyai hobi bermain games di laptop ini akan dapat memberikan rekomendasi prosuk laptop yang baik. Kemudian ada beberapa faktor yang disebutkan oleh masing-masing responden yang membuat mereka percaya kepada Opinion Leader produk laptop.

Sebanyak 1 responden dengan kode R5 menyebutkan bahwa mempercayai Orang yang dianggap Opinion Leader karena dapat memberikan saran yang baik. Responden dengan kode R9 mengatakan bahwa faktor mempercayai Opinion Leader produk laptop karena orang tersebut bergabung dalam komunitas tentang teknologi. Orang tersebut mengikuti sebuah komunitas tentang teknologi yang mana akan mendiskusikan teknologi yang baru dan menarik untuk diperhatikan. Karena hal ini responden dengan kode R9 mempercayai orang yang menjadi Opinion Leader produk laptop yang akan dibelinya. Responden dengan kode R11 dan R15 mengatakan bahwa faktor yang dapat dipercaya sebagai Opinion Leader produk laptop adalah faktor orang tersebut bekerja pada bidang teknologi. Hal ini diketahui bahwa setiap orang yang bekerja 
pada bidang teknologi akan mengerti apa produk yang mempunyai kualitas baik.

Menurut R11 dan R15, spesifikasi yang dibutuhkan pada saat R11 dan R15 menanyakan kepada orang yang menjadi Opinion Leader produk laptop terjawab dengan lengkap dan sesuai dengan apa yang dibutuhkan dan diinginkan R11 dan R15. Faktor selanjutnya disebutkan oleh responden dengan kode R14 yang menyebutkan bahwa faktor R14 mempercayai Opinion Leader adalah mengikuti mata kuliah mengenai laptop. Opinion Leader R14 adalah seorang mahasiswa yang berkuliah di jurusan Sistem Informasi ITS yang merupakan jurusan yang diambil oleh R14. Salah satu mata kuliah yang ada di jurusan Sistem Informasi ITS adalah mata kuliah mengenai laptop, oleh karena itu R14 mempercayai temannya sebagai Opinion Leader produk laptop.

Dapat disimpulkan bahwa yang paling banyak disebutkan oleh responden adalah faktor memahami masalah IT. Masalah IT yang dimaksud disini adalah pengetahuan Opinion Leader menganai laptop seperti spesifikasi laptop, harga laptop yang sesuai dengan kualitas yang bagus, merek laptop, dan mengetahui hardware dan software yang ada di produk laptop.

\section{B. Implikasi Manajerial}

Dua puluh responden membeli laptop secara offline walaupun mereka mencari informasi mengenai laptop secara online. Hal ini dikarenakan, responden akan lebih yakin jika melihat barangnya secara langsung. Hal ini sesuai dengan apa yang dikemukakan [8], bahwa kebanyakan konsumen memiliki sifat yaitu mereka akan dapat melihat dan dapat merasakan produk sebelum konsumen tersebut mengeluarkan uang yang cukup banyak. Perusahaan laptop yang memiliki website online harus dapat mengembangkan toko offline agar konsumen dapat ke toko laptop tersebut dan langsung membeli apa yang dibutuhkan oleh konsumen.

Perusahaan laptop juga dapat memanfaatkan adanya peran Opinion Leader dalam produk laptop. Sebelumnya, perusahaan harus mengetahui siapakah Opinion Leader produk laptop mahasiswa. Pada saat wawancara ditemukan bahwa, responden Opinion Leader sering kali membuka website seperti bhinneka, kaskus, toko online lainnya dan artikel yang ada di internet, dengan ini perusahaan laptop mendapatkan kesempatan untuk beriklan di website yang sudah disebutkan seperti bhinneka, kaskus, toko online lainnya dan artikel yang ada di internet. Dengan adanya iklan yang dipasang oleh perusahaan laptop, maka perusahaan laptop dapat menemukan Opinion Leader yang dapat menguntungkan perusahaan.

\section{KESIMPULAN}

Terdapat 9 faktor mahasiswa ITS mempercayai Opinion Leader yang ditemukan dalam penelian. Faktor-faktor ini diurutkan sesuai dengan seringnya faktor disebutkan oleh responden penelitian pada saat wawancara. Kesembilan faktor mahasiswa ITS mempercayai Opinion Leader adalah mereka memahami masalah teknologi, teman satu bidang atau jurusan, up to date mengenai informasi laptop, berpengalaman membeli laptop yang bagus, suka bermain games di laptop, bekerja pada bidang teknologi, dapat memberikan saran yang baik, bergabung dalam komunitas teknologi dan yang terakhir adalah mengikuti mata kuliah mengenai laptop di jurusan sistem informasi ITS. Faktor yang paling banyak disebutkan adalah faktor Opinion Leader memahami masalah IT. Masalah IT yang dimaksud adalah pengetahuan Opinion Leader menganai laptop seperti spesifikasi laptop, harga laptop yang sesuai dengan kualitas yang bagus, merek laptop, dan mengetahui hardware dan software yang ada di produk laptop.

\section{DAFTAR PUSTAKA}

[1] Suciati and N. Hidayah, "Penggunaan Laptop dalam Perkuliahan di Kelas Manfaat atau Mudharatkah?," Jurnal Pendidikan dan Kebudayaan, 2011.

[2] P. Kotler, Manajemen Pemasaran, Jakarta: PT. Prenhallindo, 2000.

[3] L. Bertrandias and R. Goldsmith, "Some Psychological Motivations for Fashion Opinion Leadership and Fashion Opinion Seeking," Journal of Fashion Marketing and Management, 2006.

[4] I. Purnomo, "Pemuka Opini Kosmetik diantara Wanita Yogyakarta," Universitas Atma Jaya, Yogyakarta, 2007.

[5] L. Schiffman and L. Kanuk, Consumer Behaviour, Global 10th Edition, USA: Pearson Education, Inc, 2010.

[6] S. A. Chaudhry and W. Irshad, "Opinion Leadership and Its Role in Buyer Decision Making," Academy of Contempory Research Journal, pp. 16-23, 2013.

[7] Solomon and Elnora, Strategi Pemasaran, Jakarta: Kelompok Gramedia, 2003.

[8] DigitalMarketer, "DIGITALMARKETER.id," 9 April 2015. [Online]. Available: https://digitalmarketer.id/mindset/antara-toko-offline-danonline-mana-yang-lebih-baik/. 